\title{
Development of Car Tyre Air Pressure System (CTAPMS) Using Node MCU ESP8266 Board
}

\section{Mohamad Faris Mohd Isha ${ }^{1}$, Ariffuddin Joret ${ }^{1 *}$, Muhammad Suhaimi Sulong ${ }^{2}$}

${ }^{1}$ Faculty of Electrical and Electronic Engineering, Universiti Tun Hussein Onn Malaysia, Batu Pahat, 86400, MALAYSIA

${ }^{2}$ Faculty of Technical and Vocational Education, Universiti Tun Hussein Onn Malaysia, Batu Pahat, 86400, MALAYSIA

*Corresponding Author

DOI: https://doi.org/10.30880/jsmt.2021.01.01.004

Received 24 August 2021; Accepted 11 October 2021; Available online 15 Disember 2021

\begin{abstract}
CTAPMS is an electronic system designed in this work to monitor the air pressure inside pneumatic tyres on various types of vehicles. A crucial issue in monitoring air pressures of a tyre was most users are too lazy and do not check their car tyre condition daily or before starting a journey. As an assist device for the user to monitor their car air tyre pressure daily, this project has developed the CTAPMS using a BMP180 sensor and Node MCU 8266 microcontroller board. Based on the system, the measured car air tyre pressure can be visualized from the ThingSpeak IoT platform through a smartphone. The performance of the developed system has been validated through a series of experimental works. The result indicates a reliable measurement with an error of less than $10 \%$ as compare to the existing system. Further, this product will be commercialized for future use.
\end{abstract}

Keywords: Internet of Things, tyre pressure monitoring system, arduino, ThingSpeak

\section{Introduction}

Nowadays, car accidents are one of the main causes of death in Malaysia. There are many factors that the accidents occurred and for certain cases due to the pressure variation in car's tyres. The global rate of road traffic death is 18.2 per 100,000 populations; there is significant variation across the world's regions, where the rate of death ranges from 9.3 to 26.6 per 100,000 populations. Regional rates of road traffic deaths in Africa and South-East Asia are highest at 26.6 and 20.7 deaths per 100,000 populations respectively (WHO, 2018). Road traffic accidents (RTA) in Malaysia were recorded as the highest fatality rate (per 100,000 populations) among the ASEAN countries (Norziha et al., 2018). Most of the accidents are caused by the pressure variation in car's tyres. Due to this, a car will have tyre pressure effects on handling that can cause a lost control while driving. The main reason for this situation could happen due to less or no monitoring of the tyre pressure had been done by the user before entering on their vehicle.

The recommended nominal car tyre inflation pressure always refers to the cold tyre. The pressure inside a warm tyre, after a period of normal driving, when the heat builds up, is natural to increase (Continental, 2016). By referring to Michelin and Goodyear tyre manufacturers, a reduction in tyre life of up to $30 \%$ if the tyre is used with a pressure value $20 \%$ lower compared to the recommended one (PressureGuard ${ }^{\mathrm{TM}}, 2013$ ).

Hence, Tyre Pressure Monitoring System (TPMS) were introduced in the newest vehicle model. An indicator light will be appearing as a warning in a screen display if the tyre pressure was in low condition. It can avoid many serious car accidents when a user knows their car tyre pressure level.

In this project, a prototype system of a car tyre air pressure system (CTAPMS) has been developed. The aim of the prototype system is to assist the user to monitor their car tyres air pressure by using the Node MCU ESPESP8266 
microcontroller board. This system is also using an IoT application to collect the data online using the ThingSpeak platform. By using this system user which is the car driver of the car can identify the car tyres air pressure at any time in any place of the world even at a distance that is far away from the car.

\section{Materials and Methods}

This project proposes a car tyre air pressure system that can automatically monitor the air pressure in a car tyre. The air pressure is monitored by pressure sensor BMP180 that are attached to a tyre. Next, a microcontroller board Node MCU ESP8266 is used to run the system algorithm and also to provide a wireless network between system and user through the Internet of Things (IoT) platform. All the data has been transmitted to the selected IoT platform which is ThingSpeak. Fig. 1 shows the flowchart operation of CTAPMS.

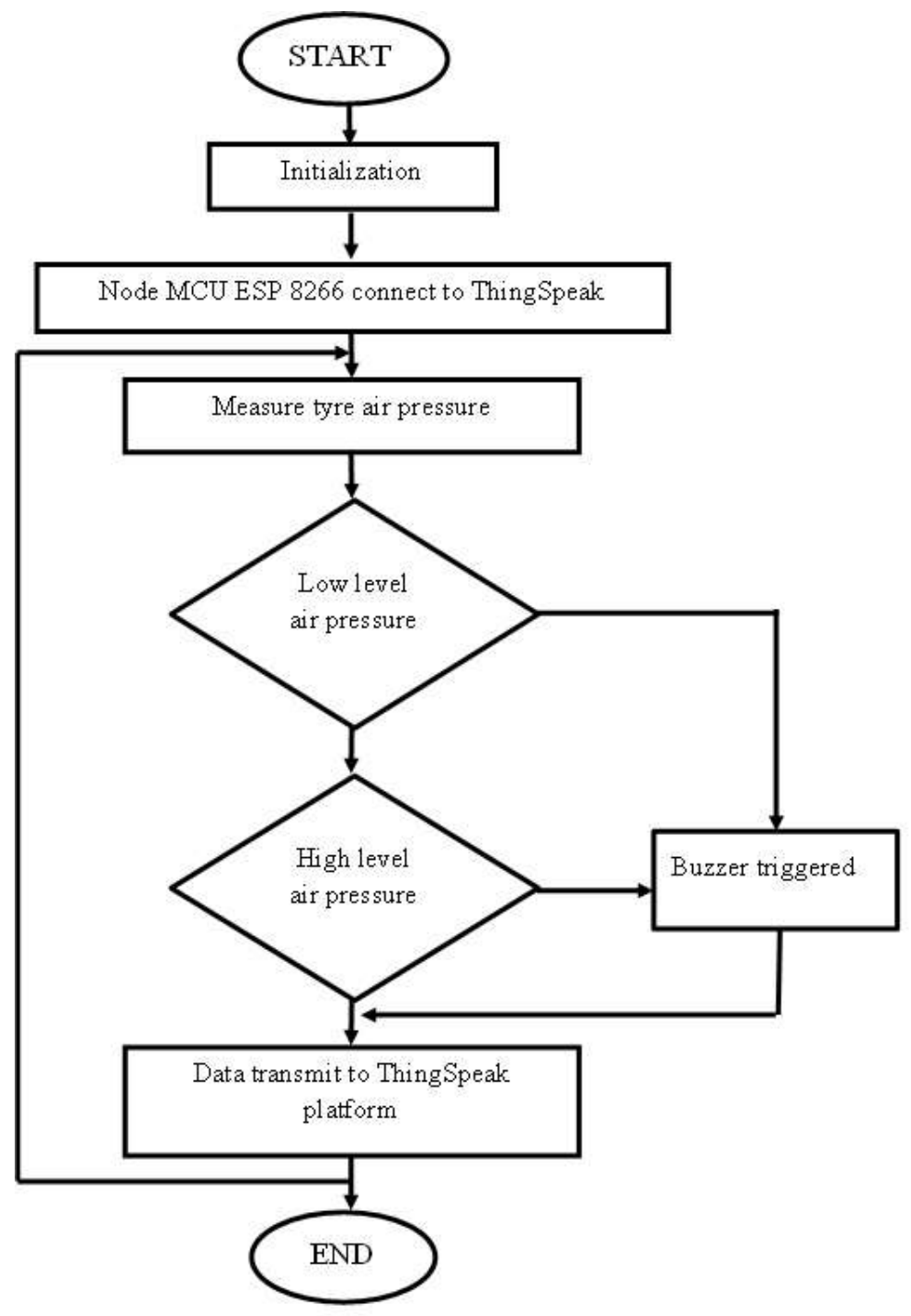

Fig. 1 - Flowchart of CTAPMS

Based on Fig. 1, the system will start connecting the Node MCU ESP8266 board to ThingSpeak as an IoT platform after initialization. Then, the sensor will start sensing the pressure in the attached tyre. Referring to the measuring data, the microcontroller board will trigger the alarm system which has been connected if the reading value is below or above the threshold value set. The measured data will be transmitted to the IoT platform for monitoring purposes where the analysis of the data can be done to predict the lifespan of the tyre.

Fig. 2 shows the block diagram of CTAPMS which consist of a pressure sensor BMP180, microcontroller Node MCU ESP8266 board and ThingSpeak IoT platform. Based on this figure, the pressure sensor which is acting as an input device will sense the air pressure inside a tyre. Then the measured pressure data will be collected by the 
microcontroller to be sent to the IoT platform. In the ThingSpeak platform, the measured tyre air pressure will be analyzed to estimate the condition of the tyre such as predicted its lifespan.

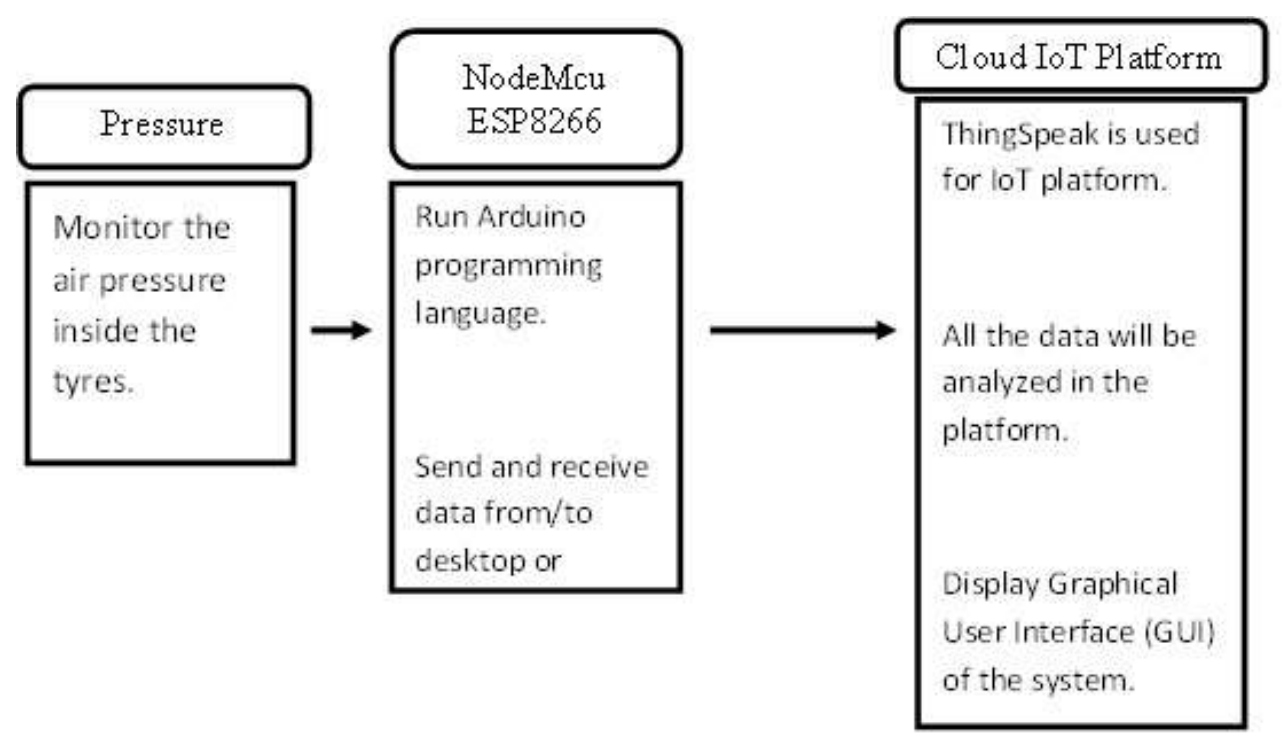

Fig. 2 - CTAPMS block diagram

\section{Equations}

In this work, the algorithm of the microcontroller board used has been programmed using Arduino IDE. As the BMP180 pressure sensor produced an output value in pascal (ps), the calculation used to convert the measured data from ps to standard per square inch (psi) value is based on equation (1).

$$
P s i=P a \times 0.00014503773
$$

\section{Results and Discussions}

The experiment conducted in this work to test the functionality and efficiency of the hardware which is a pressure sensor has been done using a single car tyre. In this work, the hardware of the system has been designed which included the hardware casing.

\subsection{D Model}

Fig. 3(a) shows the bottom view of the hardware casing designed in this work using Google Sketchup. The pressure sensor will be put at the bottom of the casing which will then be attached to the tyre. The rest of the components which are the microcontroller and battery will be put on the top of the sensor. There are 3 sections that are included in this casing which is top for battery installation, the middle section for the microcontroller board while the bottom section is the place where the pressure sensor is put.

The complete hardware system design is as shown in Fig. 3(b). The casing of the hardware has been developed using Perspex material. 

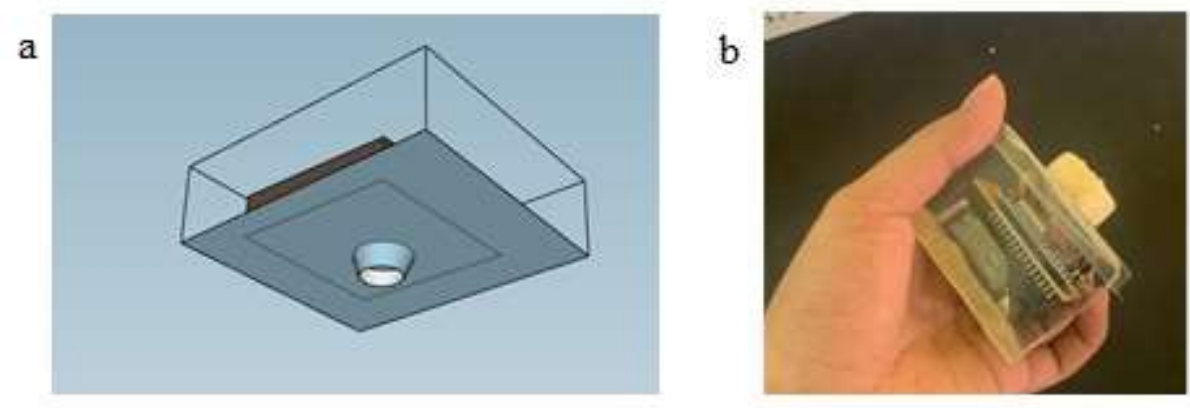

Fig. 3 - (a) Bottom view of the casing design; (b) hardware system of CTAPMS

\subsection{Pressure Sensor Measurement Test}

The aim of this experiment is to evaluate the functionality and capability of the pressure sensors in determining the level of pressure in a car tyre. The pressure sensor is installed into a holder and the sensor holder is mounted on the potential part of the car rim. Fig. 4 show the schematic diagram of the CTAPMS designed in this work.

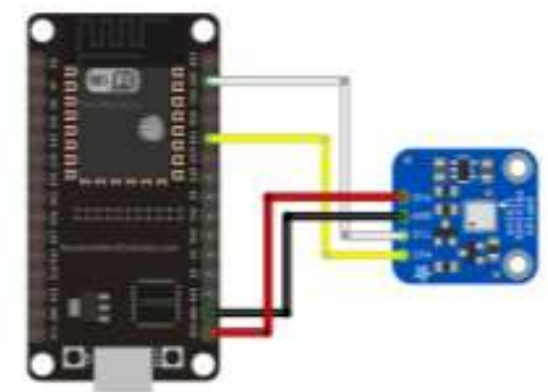

Fig. 4 - Schematic diagram for pressure sensor

\subsection{The Effectiveness of the CTAPMS}

Table 1 shows the comparison results between commercialized TPMS and CTAPMS systems developed in this work using microcontroller Node MCU ESP8266 board. The comparison has been done for 5 days using a tyre of Perodua Myvi. Before starting the experiment, the air pressure tyre of the Myvi has been set to 31 psi. Based on Table 3.1 , the measuring results between the two systems seem to have some different values. However, the error percentage between the two systems is less than $10 \%$.

Table 1 - Results Comparison

\begin{tabular}{cccc}
\hline Day & $\begin{array}{c}\text { Commercialize } \\
\text { TPMS (psi) }\end{array}$ & $\begin{array}{c}\text { CTAPMS } \\
\text { (psi) }\end{array}$ & $\begin{array}{c}\text { Percentage } \\
\text { Error \% }\end{array}$ \\
\hline 1 & 30 & 28 & 6.67 \\
2 & 30 & 27 & 10 \\
3 & 29 & 28 & 3.45 \\
4 & 30 & 28 & 6.67 \\
5 & 31 & 29 & 6.45 \\
\hline
\end{tabular}

\subsection{IoT Based CTAPMS System}

In testing the developed CTAPMS system in this work, which is able to transmit the data to the IoT platform, the sensor BMP180 has been mounted in-car wheel to measure the air pressure of the tyre. A rubber sheet was attached to the sensor surface to hold the bleed button on the side of the tyre gauge for a few seconds to release some air from the tyre. Fig. 5 shows the measurement results of the developed system displayed in the ThinkSpeak platform. 


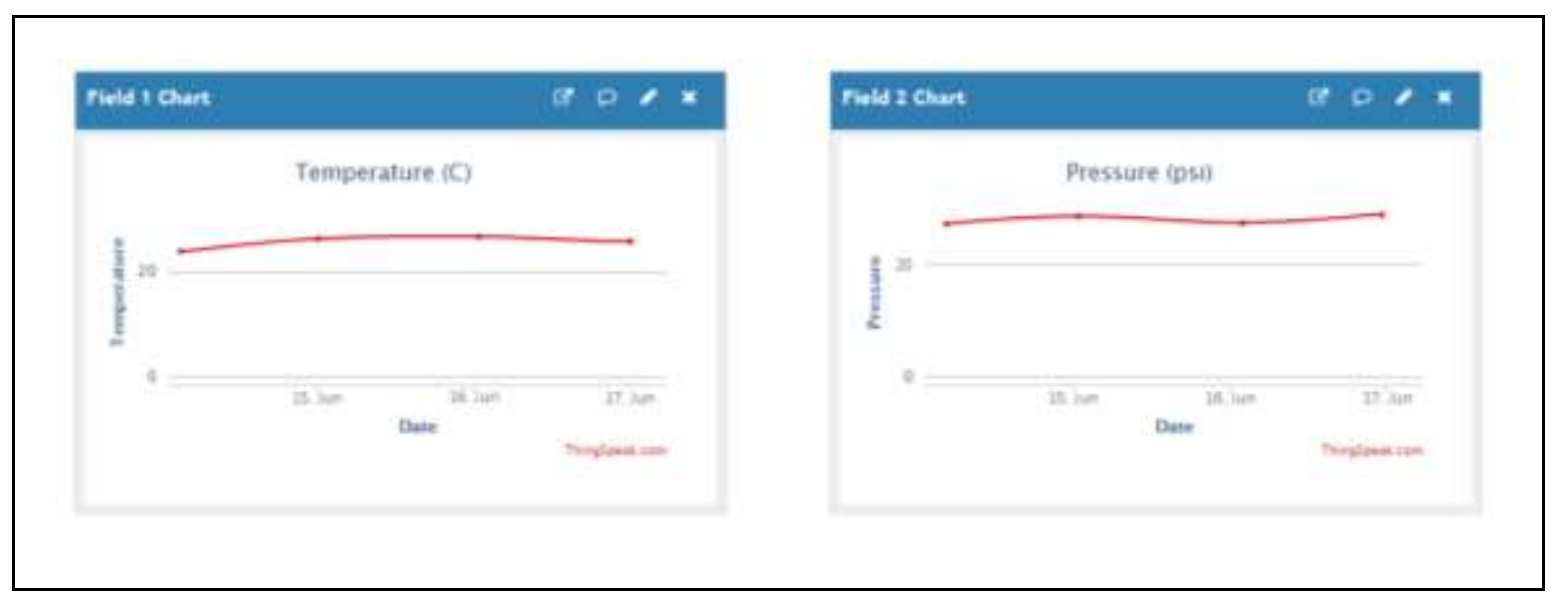

Fig. 5 - Result of real time data on the ThingSpeak

\subsection{Result in Rainy Day between Commercialize TPMS and CTAPMS}

Table 2 shows the results of car air tyre pressure measurement by TPMS and developed CTAPMS system on rainy days. In this measuring procedure, the Perodua Alza's car tyre has been used as a testing subject. Based on Table 2, the measurement of the two systems seems to produce some errors which are less than $10 \%$.

Table 2 - Results comparison

\begin{tabular}{cccc}
\hline Day & $\begin{array}{c}\text { Commercialize } \\
\text { TPMS (psi) }\end{array}$ & $\begin{array}{c}\text { CTAPMS } \\
\text { (psi) }\end{array}$ & $\begin{array}{c}\text { Percentage } \\
\text { Error \% }\end{array}$ \\
\hline 1 & 28 & 27 & 3.45 \\
2 & 29 & 29 & 0 \\
3 & 29 & 28 & 3.45 \\
4 & 30 & 27 & 10 \\
5 & 29 & 28 & 3.45 \\
\hline
\end{tabular}

\subsection{Result in Sunny Day between Commercialize TPMS and CTAPMS}

Table 3 shows the comparison measurement results between the commercialised TPMS and the CTAPMS systems on a sunny days. Again, as referring to this table, the error in measurement between the two systems is less than $10 \%$.

Table 3 - Results comparison

\begin{tabular}{cccc}
\hline Day & $\begin{array}{c}\text { Commercialize } \\
\text { TPMS (psi) }\end{array}$ & $\begin{array}{c}\text { CTAPMS } \\
(\mathbf{p s i})\end{array}$ & $\begin{array}{c}\text { Percentage } \\
\text { Error \% }\end{array}$ \\
\hline 1 & 29 & 27 & 6.9 \\
2 & 31 & 28 & 9.68 \\
3 & 32 & 30 & 6.25 \\
4 & 30 & 28 & 6.67 \\
5 & 30 & 27 & 10 \\
\hline
\end{tabular}

\section{Conclusion}

In conclusion, the CTAPMS system developed in this work can be considered reliable as it produces a measurement error of less than $10 \%$ as compared to the commercialised TPMS system. As IoT based system, the measurement done using the proposed CTAPMS can be viewed through smartphone at ThingSpeak platform make the system easy to be used. This indirectly can assist the users to monitor their car air tyre pressure anywhere in this world at any time. 


\section{Acknowledgement}

The authors would also like to thank the Universiti Tun Hussein Onn Malaysia for its support.

\section{References}

[1] Ali, B., Akram, B. \& Jameel, U. (2012). Tyre pressure monitoring system. Universiti Tun Hussein Onn Malaysia: Bachelor Degree Thesis, 2012

[2] Continential AG (2016). Technical datebook car-4x4-van 2015-2016. Continential The Future in Motion, Selangor, Malaysia. Retrieved November 23, 2021, from website: https://www.continentaltyres.com.my/car/technology

[3] Hannan, M. A., Hussain, A., Mohamaed, A. \& Samad, S. A. (2008). TPMS data analysis for enhancing intelligent vehicle performance. Journal of Applied Science, 8(10), pp. 1926-1931

[4] Mallidi, S. K. R. \& Vineela, V. V. (2018). IoT based smart vehicle monitoring system. International Journal of Advanced Research in Computer Science, 9(2), pp. 738-741

[5] Norziha Che-Him et al. (2018). Factors Affecting Road Traffic Accident in Batu Pahat, Johor, Malaysia. Journal of Physics: Conference Series, 995, 012033

[6] PressureGuard ${ }^{\mathrm{TM}}$ (2013): Industry Standard on Tyre Pressure Effects, Fleet Air LLC, Cleveland, U.S.A. Retrieved November 23, 2021, from website: http://www.fleetair.com/wpcontent/uploads/ Industry_Info_on_Effects.pdf

[7] Salunkhe, P. G., Kulthe, H. R., Kolhem, S. N. \& Khan, A. A. (2017). Automatic tyre pressure monitoring system using wireless communication. International Journal of Advance Research in Science and Engineering, 6(3), pp. 471-479

[8] Sodano, H. A., Park, G., \& Inman, D. J. (2004). Estimation of electric charge output for piezoelectric energy harvesting. International Journal for Experimental Mechanics, 40(2), pp. 49-58

[9] Vijaya, V. G., Hameed, H. J. \& Dhanasekar, J. (2017). Design and implementatation of wheel pressure monitoring system. International Journal of Pure and Applied Mathematics, 116(14), pp. 75-80

[10] WHO (2018). Global status report on road safety 2018. Geneva: World Health Organization, Jun 17, 2018

[11] Wolfson, M. \& Felker, D. (2013). Android developer tools essentials: Android Studio to Zipalign. California: O'Reilly Media, Inc 